\title{
ULTRASOUND MEASUREMENTS FOR BODY CONDITION SCORE ASSESSMENT OF DAIRY Cows
}

\author{
JANZEKOVIC, M.; MOCNIK, U. \& BRUS, M.
}

Abstract: Body condition score (BCS) is in high correlation with health status of animal, metabolic disorders and milk composition during the production period. The objective of our research was to compare and present reliable and suitable methods for everyday use for assessing body condition score of cows.

The study was investigating the use of ultrasound to determine the BCS of dairy cows. It included 41 dairy cows, of which 10 were Holstein Friesians, 13 Simmentals and 18 crossbreeds. We compared the BCS of the cows based on the subjective assessments of two experienced assessors and evaluations based on the ultrasound of the fat tissue thickness. We discovered that there are no statistically significant differences except for the breed related differences. While the BCS of Simmentals, which amounts to $3.71 \pm 0.52$ does not differ from the condition of the crossbreeds, which amounts to $3.76 \pm 0.36$, it differs from the condition of the Holstein Friesian, which is $3.25 \pm 0.39$.

Key words: ultrasound, dairy cows, body condition, reliable methods, suitable methods
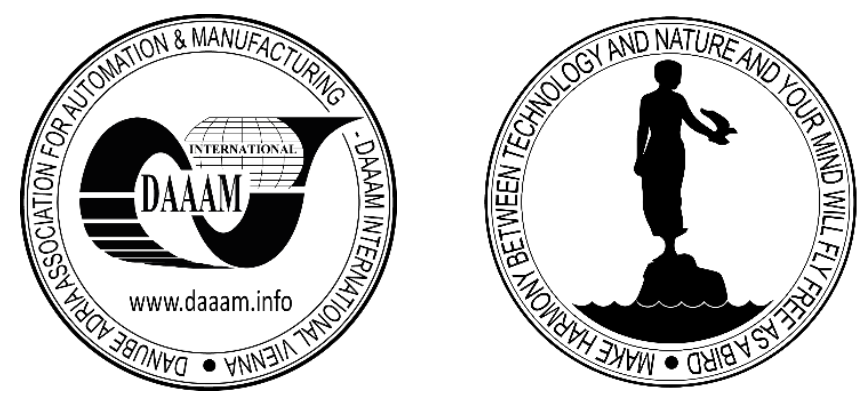

Authors' data: Assist. Prof. PhD. Janzekovic, M[arjan]; Mocnik, U[rska]; M. Sc. Brus, M[aksimiljan], University of Maribor, Faculty of Agriculture and Life Sciences, Pivola 10, 2311, Hoce, Slovenia, marjan.janzekovic@um.si, ursamocnik@gmail.com, maksimiljan.brus@um.si

This Publication has to be referred as: Janzekovic, M[arjan]; Mocnik, U[rska] \& Brus, M[aksimilijan] (2015). Ultrasound Measurements for Body Condition Score Assessment of Dairy Cows, Chapter 05 in DAAAM International Scientific Book 2015, pp.051-058, B. Katalinic (Ed.), Published by DAAAM International, ISBN 9783-902734-05-1, ISSN 1726-9687, Vienna, Austria

DOI: $10.2507 /$ daaam.scibook.2015.05 


\section{Introduction}

Cow condition score represents a visual or tactile estimation (or both) of the quantity of subcutaneous fat as energy reserves on a cow body (Schröder \& Staufenbiel, 2006) or automatic systems (Bauer et al., 2012). Estimation value usually range from 1 to 12, depending on the evaluation system used by the assessor (Domecq et al., 1995). Bewley \& Schutz (2008) have examined the condition estimation systems renowned throughout the world. Animals are estimated tactile in Ireland, the UK and New Zealand, but visual estimations are placed in the USA, Australia and Denmark.

Body condition score (BCS) is an indicator of how well the animals maintain their energy reserves, which reflects the relation between the cows nutrient supply and milk production. It represents also a subjective assessment of the amount of fat or energy stored in cow's body. Condition score is a good indicator of cow's energy metabolism through lactation and can be reliable criterion to balance the relation between milk production and feed intake (Klopcic et al., 2011; Gruber et al., 2014). The composition of feed ration is extremely important for maximum feed consummation. This should be calculated on the basis of the applicable feed norms and balanced very well. The modern information technology enables fast and efficient solving of mathematical programs with large number of variables and constraints. Since many modern optimization tools operate in spreadsheet environment, the results of optimization models can be directly linked to enterprise budgets in the form of decision support systems and that enables efficient and successful management of dairy cow operation. However, the model formulation requires expertise in mathematical programming as well as animal nutrition. (Janzekovic et al., 2014).

In general, the condition score is considered as an important tool in the dairy cows breeding, because it is simple and repeatable system for evaluation of energy reserves and changes in the their condition score. It is related to the performance of reproduction, where the cows with poor condition score are more subject to the reproduction problems and the condition acquisition has positive effect on the days to the first estrus, intervals of first insemination and success rate at first insemination and negative impacts on the number of calving and insemination on one cow (Azzaro et al., 2011). Over-fat cows are during the dry period more subject to metabolic, infectious, gastrointestinal and reproductive disorders (Schröder \& Staufenbiel, 2006).

\section{Materials and methods}

\subsection{Cattle}

In this study we have included cattle of 41 dairy cows of different breeds: 13 Simmental cows, 10 Black-and-white cows and 18 crossbreed cows. Cows have performed in various successive lactations (lactations from 1 to 7 ) and in different lactation stages.

\subsection{Condition scoring}

Body condition scoring is a useful tool for distinguishing nutritional needs in the dairy herd on the basis of subcutaneous fat. Condition score is a better indicator of 
nutritional and energy status of cows as the live weight, that changes irrespective of animal's care. In addition, studies were implemented on the validity of measuring the quantity of subcutaneous fat by using ultrasonic scanning. These studies report about high correlations between ultrasonic measurements and condition score, suggesting that condition score reflects the actual quantity of subcutaneous fat (Zulu et al., 2001; Spur et al., 2010). Domecq et al. (1995) have indicated that the correlation coefficients have ranged from 0.36 to 0.86 , and they all were statistically different $(\mathrm{p}<0.05)$.

Cow's condition score was estimated by two trained assessors the day before our measurements at a scale of 1 to 5, with one-quarter levels. This assessment was conducted in a way that the second assessor began with the assessment when the first ended. In assessing the first assessor the second assessor was not present.

\subsection{Measurement method}

On the day of measurement the cows were fixed individually in self-locking manger in order to calm down and shaved on designated areas of measurement. There were three measure points, namely: the last rib, flank and thigh. All the measurements were performed on the left side of the animal, the measure-unit were millimeters (mm).

\subsubsection{Skinfold measurement}

Skinfold was measured with skinfold caliper (in $\mathrm{mm}$ ) at three different points. First, we measured skinfold at the last rib (skinfold 1), at the flank (skinfold 2) in and at the thigh (skinfold 3).

\subsubsection{Ultrasonic measurements}

For measurement of subcutaneous fat (in mm) a Dramiński animal scanner was used. A probe of the device we have coated with a gel in order to provide better contact and consequently a better image in the measurement performance. The measurement was performed at three different points: the last rib (ultrasound 1), between hip's knot and sitting knot (ultrasound 2) and between hip's knot and spine (ultrasound 3).

\subsection{Equipment}

Dramiński animal scanner is a portable ultrasonic scanner for professional diagnosis in small and large animal reproduction (Fig.1). This is a first ultrasonic scanner for professional use, which includes a full portability, superior picture quality and outstanding durability.

\subsubsection{Scanner features}

Versatile ultrasound scanner

It cooperates with different kinds of sector and mechanical (abdominal and endorectal) probes. It gives broad possibilities for examining a variety of animals, such as cows, mares, sheep, pigs, goats, dogs, camels, alpaca and even dolphins.

Professional image quality

Owing to specialized sector and mechanical probes, the obtained image allows for effective diagnosis of examined animals. A wide imaging angle of the rectal probe $\left(180^{\circ}\right)$ assures fast and easy examination. 


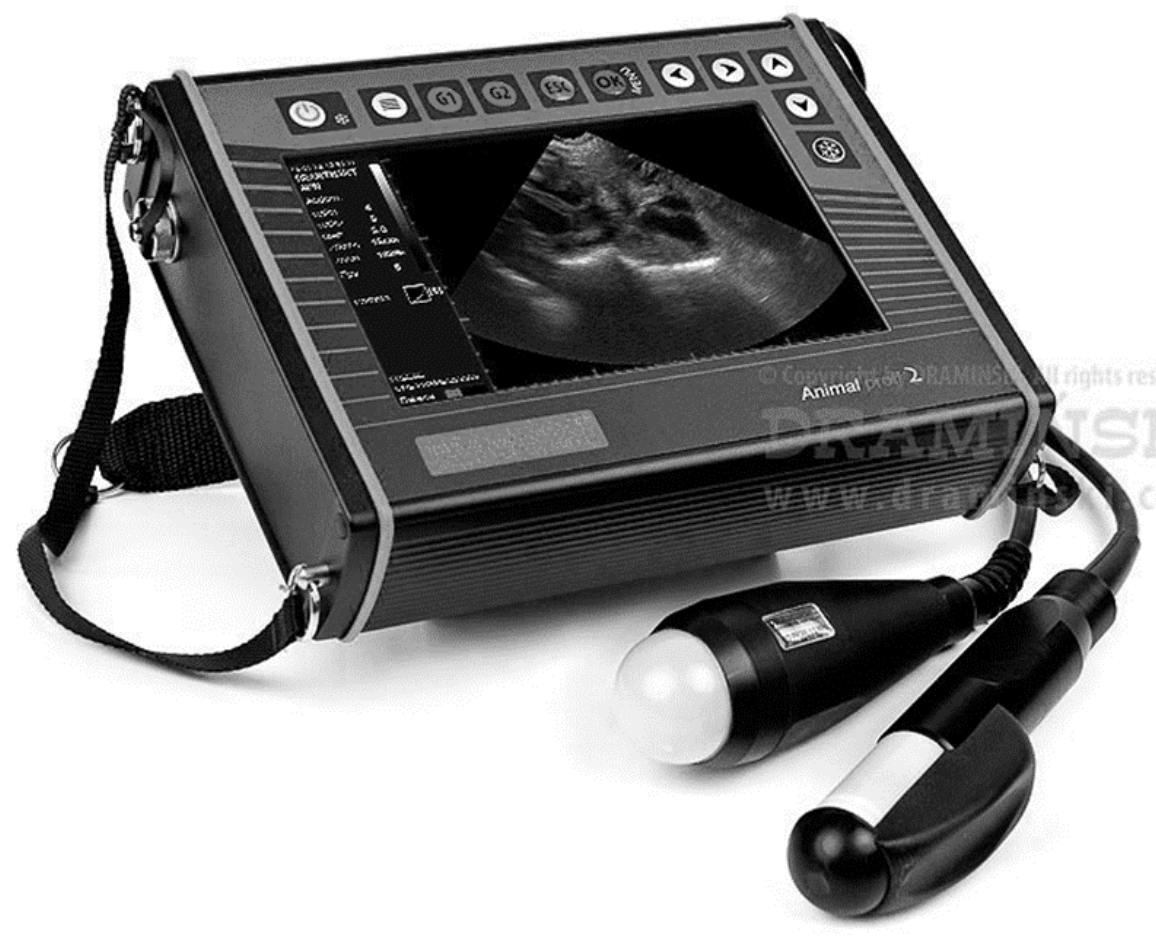

Fig. 1. Dramiński ultrasound scanner (www.draminski.com)

High functionality

The distinctive features of the ultrasound are:

- $\mathrm{B}$ and $\mathrm{B}+\mathrm{B}$ Mode imaging,

- a large 6.4" LCD screen with high contrast,

- memory of up to 200 images,

- image labeling of recorded animals; number and date of examination,

- video loop (cine loop),

- double zoom,

- membrane keyboard, very easy to clean,

- efficient sources of power to guarantee many hours of operation,

- special visor to work in full sun,

- easy handling in practical conditions

- possibility of connecting the device to the computer via USB2.0,

Exceptional strength

- strong, aluminum casing to guarantee reliable operation,

- high resistance to water, dust and other dirt,

- ultrasound probes with high mechanical resistance,

High mobility

Ultra-compact size - weight and size - as well as a special, four-point harness system for easy work with animals in harsh conditions. Owing to a special explorer case transport of the device is very easy. 


\subsection{Statistical analysis}

The database was designed in programming environment of Microsoft Excel 2010 and statistical analysis was made by SPSS statistical program package (Darren \& Mallery, 2013). The statistical comparison consisted of the following characteristics:

- cow's condition score

- thickness of the skinfold and subcutaneous fat thickness at the last rib (skinfold 1 and ultrasound 1)

- thickness of skinfold on the flank (skinfold 2)

- thickness of skinfold on the thigh (skinfold 3)

- subcutaneous fat thickness between hip's knot and sitting knot (ultrasound 2)

- subcutaneous fat thickness hip's knot and spine (ultrasound 3)

To calculate the average values and standard deviations a procedure Descriptive Statistics was used and to determine statistically significant differences we choose an operation One-way-ANOVA. Differences between means were tested by a Post hoc Tukey test and are statistically significant at value of $p<0.05$.

In order to determine the correlation of examined individual characteristics we have used a linear correlation. In correlation tables the Pearson correlation coefficients are shown. Characteristics are mutually statistically significant correlated at values of $\mathrm{p} \leq 0.05$ and $\mathrm{p} \leq 0.01$.

\section{Results with discussion}

\subsection{Condition comparison depending on the breed}

Values in table 1 shove that there are the differences in condition score of individual breeds. Zulu et al. (2001) state in their publication that the condition score of Black and white breed ranged from 2.25 to 4.25 , in averaged value of $3.22 \pm 0.09$. In our case the condition score of Black and white breed was $3.25 \pm 0.39$ and is statistically significant $(\mathrm{p}<0.05)$ different from the condition score of Simmental breed or crossbred cows.

\begin{tabular}{|c|ccc|}
\hline Trait & Black and white & Simmental & Crossbreed \\
\hline N & 10 & 13 & 18 \\
BCS & $3.25 \pm 0.39^{\mathrm{a}}$ & $3.71 \pm 0.52^{\mathrm{b}}$ & $3.76 \pm 0.36^{\mathrm{b}}$ \\
SF 1 & $14.00 \pm 2.83^{\mathrm{a}}$ & $17.54 \pm 2.07^{\mathrm{b}}$ & $16.06 \pm 2.71^{\mathrm{ab}}$ \\
SF 2 & $12.50 \pm 2.32^{\mathrm{a}}$ & $17.33 \pm 3.34^{\mathrm{b}}$ & $15.61 \pm 3.10^{\mathrm{b}}$ \\
SF 3 & $12.30 \pm 2.45$ & $14.08 \pm 2.18$ & $13.17 \pm 2.26$ \\
US 1 & $9.00 \pm 2.21$ & $6.62 \pm 1.61$ & $7.89 \pm 2.70$ \\
US 2 & $7.40 \pm 1.58$ & $8.46 \pm 2.40$ & $7.33 \pm 1.41$ \\
US 3 & $7.30 \pm 2.16$ & $7.54 \pm 1.94$ & $7.39 \pm 2.45$ \\
\hline
\end{tabular}

$\mathrm{a}, \mathrm{b}-$ average values marked with different letters in column are significantly different at $\mathrm{p}<0.05$.

BCS - body condition score, SF - skinfold, US - ultrasound

Tab.1. Comparison of body condition between breeds 
When compared skinfold 1 we found it distinguishes by black-and-white breed and Simmental breed but it is equal by black-and-white breed and crossbred cattle. Similarly, skinfold 2 of mottled breed is equal to crossbred cattle, but it distinguishes relating to black-and-white cows. In the comparison of skinfold 3 there are no statistically significant differences between different breeds.

Zulu et al. (2001) indicate that the ultrasonic measurements of subcutaneous fat extended in range from 1.30 to $16.00 \mathrm{~mm}$. They also indicate the condition score was positive correlated to subcutaneous fat ultrasonic measurements at all three measure areas. In our case, ultrasonic measurements 1 in black-and-white breed which values amounted to $9.00 \pm 2.21$, are not statistically significant different from ultrasonic measurements 1 of Simmental breed, which values amounted to $6.62 \pm 1.61$, and ultrasonic measurements 1 in crossbred cows, which values were $7.89 \pm 2.70$. The same results perform by ultrasonic measurements 2 and 3, where no statistically significant differences between individual breeds were found.

\subsection{Condition score comparison on successive lactation}

When ultrasound 1 we found there are no statistically significant differences in individual successive lactations. By ultrasound 1 in first lactation the condition score amounted in value of $7.50 \pm 2.32$, in the second lactation $7.63 \pm 2.00$, in the third 8.00 \pm 3.20 , in the fourth and any subsequent lactations $7.91 \pm 2.26$. Even by ultrasonic measurements on areas 2 and 3 there are no statistically significant differences between individual lactations.

\begin{tabular}{|l|ccccccc|}
\hline Trait & BC & SF 1 & SF 2 & SF 3 & US 1 & US 2 & US 3 \\
\hline BC & 1 & $0.531^{* *}$ & $0.376^{*}$ & $0.348^{*}$ & -0.034 & 0.028 & 0.078 \\
SF 1 & & 1 & $0.615^{* *}$ & $0.514^{* *}$ & 0.030 & -0.042 & -0.046 \\
SF 2 & & & 1 & $0.504^{* *}$ & -0.096 & 0.095 & 0.115 \\
SF 3 & & & & 1 & 0.056 & -0.146 & 0.157 \\
US 1 & & & & & 1 & 0.012 & $0.358^{*}$ \\
US 2 & & & & & & 1 & -0.124 \\
US 3 & & & & & & & 1 \\
\hline
\end{tabular}

$* \mathrm{p} \leq 0.05$ - statistically significant correlation, ${ }^{* *} \mathrm{p} \leq 0.01-$ statistically significant correlation.

BC - body condition, SF - skinfold, US - ultrasound

Tab. 2. Linear correlation coefficients between the measurements

\subsection{Condition score comparison on the stage of lactation}

By ultrasonic measurement 1 was found there are no statistically significant differences between different stages of lactation. MacDonald et al. (1999) in conclusion of their study indicate that ultrasonic measurements of the depth of the fat on the ribs and the hips do not improve the ability to estimate levels of body reserves. Also they note that the animals in the middle of lactation have had at least of 
subcutaneous fat. By ultrasonic measurements on areas 2 and 3 it was found there are no statistically significant differences between individual stages of lactations.

\subsection{Condition score correlation to subcutaneous fat measurement}

Table 2 shows correlation coefficients between measurements regardless of the breed. It can be seen the condition score is statistically significant positive correlated to skinfold $1(\mathrm{p}<0.01)$, skinfold $2(\mathrm{p}<0.05)$ and skinfold $3(\mathrm{p}<0.05)$. This means that the higher is the condition score of cows, the bigger is thickness of the skin folds 1,2 and 3. Also, there are statistically significant positive correlated skin folds 1, 2 and 3 ( $\mathrm{p}<0.01$ ), which indicates that if increasing the skinfold 1 , also skin folds 2 and 3 will increase.

\section{Conclusions}

In practical conditions of the dairy cows rearing is very important quality assessment of the body condition (BC) for the healthy and efficient productivity of milk. Important effect of the $\mathrm{BC}$ is in pre and postpartum period influence on the animal health status which results in the obtained height of lactation cure and milk persistency till the end of lactation.

Condition score determination is an important tool for the proper care and nutrition of dairy cows. In our study we tried to find out whether is possible to determine the condition status of individual cows with ultrasonic measurement.

The lowest condition score was found on black-and-white cattle, while between Simmental and crossbred cattle there are no statistically significant differences.

When measuring skin folds the lowest values performed by black-and-white cattle, followed by crossbred cattle and then the Simmental breed.

When measured by ultrasound the black-and-white cattle have had the highest thickness of subcutaneous fat, followed by crossbred cattle and then the mottled breed. The highest subcutaneous fat and the lowest condition score of black-and-white cows can be explained by the fact, that the crossbred and mottled cattle use the excess energy from the meal consumed for the muscle mass formation and not for fat creation as it happens with the black-and-white cattle.

In condition score compared on successive lactation the cows in $1^{\text {st }}$ lactation have had higher condition score than cows in $2^{\text {nd }}$ lactation, but lower than cows in $3^{\text {rd }}$ lactation. Cows in $2^{\text {nd }}$ lactation have had lower condition score than cows in $3^{\text {rd }}$ lactation. In condition score evaluation according to the stage of the lactation it was found that the condition score vary normally, because it at the beginning of lactation is higher, then drops slightly and at the end of the lactation increases again. In the blackand-white breed is at the beginning of the lactation (for the first 100 days) the condition score highest, by increasing the number of days in stage of the lactation from 101-200 days it drops for a bit, but in stage of the lactation for over 200 days starts to rise again. Crossbred and Simmental cattle had similar pattern of individual BCS in lactation stages.

While determining the correlations between measurements and condition score we have found that is mostly a positive statistically significant correlation between subcutaneous fat and thickness of the skinfold 1 . As we have found that not only the 
Janzekovic, M.; Mocnik, U. \& Brus, M.: Ultrasound Measurements for Body Condi...

thickness of subcutaneous fat affects the condition score but also the amount of muscle tissue, it would be necessary for further research to measure the thickness thereof.

\section{References}

Azzaro, G.; Caccamo, M.; Ferguson, J.D.; Battiato, S.; Farinella, G.M.; Guarnera, G.C.; Puglisi, G.; Petriglieri, R. \& Licitra, G. (2011). Objective estimation of body condition score by modeling cow body shape from digital images. Journal of Diary Science, 94(4): 2126-2137, ISSN: 0022-0302

Bauer, U.; Harms, J.; Steyer, M.; Salau, J.; Haas, J.H.; Weber, A.; Junge, W.; Bieletzki, S.; Rothfuss, H. \& Suhr, O. (2012). Automatic monitoring of the body condition score of dairy cows. Landtechnik, 67(6), 409-412, ISSN 0023-8082

Bewley, J.M. \& Schutz, M.M. (2008). An interdisciplinary review of body condition scoring for dairy cattle. Professional Animal Scientist, 24: 507-529, ISSN: 1080-7446 Domecq, J.J.; Skidmore, L.A.; Lloyd, J.W. \& Kaneene, J.B. (1995). Validation of body condition scores with ultrasound measurements of subcutaneous fat in dairy cows. Journal of Diary Science, 78: 2308-2313, ISSN: 0022-0302

Gruber, L.; Urdl, M.; Obritzhauser, W.; Schauer, A.; Häusler, J. \& Steiner, B. (2014). Influence of energy and nutrient supply pre and postpartum on performance of multiparous Simmental, Brown Swiss and Holstein cows in early lactation. Animal, 8(1): 58-71, ISSN: 1751-7311

Darren, G. \& Mallery, P. (2013). IBM SPSS Statistics 21 Step by Step: A Simple Guide and Reference, 13th Edition. Pearson, pp. 416, ISBN-13:978-0205985517, ISBN10:0205985513, Canadian University College

Janzekovic, M.; Rozman, C.; Pazek, K. \& Pevec, P. (2014). Mathematical Model for Balancing Feed Rations in Dairy Cows, In: DAAAM International Scientific Book 2014, Katalinic, B. (Ed.), pp. 153-162, Published by DAAAM International, ISBN 978-3-90150998-8, ISSN: 1726-9687, Vienna, Austria

Klopcic, M.; Hamoen, A. \& Bewley, J. (2011). Body condition scoring of dairy cows. Biotechnical. Faculty, Department of Animal Science, Domzale: 7, ISBN: 978-9616204-54-5

MacDonald, K.A.; Penno, J.W. \& Verkerk, G.A. (1999). Validation of body condition scoring by using ultrasound measurement of subcutaneous fat. Proceeding of the New Zealand Society of Animal Production, 59: 177-179, ISSN: 0370-2731

Schröder, U.J. \& Staufenbiel, R. (2006). Invited review: Methods to determine body fat reserves in the dairy cow with special regard to ultrasonographic measurement of backfat thickness. Journal of Diary Science, 89: 1-14, ISSN: 0022-0302

Spur, M.; Tanzler, J.; Smolinger, J. \& Klopcic, M. (2010). Linear scoring of Simmental breed. Ministry of agriculture forestry and food of Slovenia. Ljubljana: 40, ISBN: 978961-6761-15-4

Zulu, V.; Nakao, T.; Moriyoshi, M.; Nakada, K.; Sawamukai, Y.; Tanaka, Y. \& Zhang, W. (2001). Relationship between body condition score and ultrasonographic measurement of subcutaneous fat in dairy cows. Journal of Diary Science, 6: 816-820, ISSN: 0022-0302

*** http://www.draminski.com - Draminski ultrasound scanners, Accesed on: 201502-03 